\title{
How Safe is your Curry? Food Allergy Awareness of Restaurant Staff
}

Lucy AR Common ${ }^{1,2}$, Christopher J Corrigan ${ }^{3}$, Helen Smith ${ }^{4 *}$, Sam Bailey4, Scott Harris ${ }^{2}$ and Judith A Holloway ${ }^{2}$

${ }^{1}$ Immunology Department, Salford Royal NHS Foundation Trust, Salford, UK

${ }^{2} \mathrm{MSc}$ Allergy, Faculty of Medicine, University of Southampton, Southampton, UK

${ }^{3}$ Department of Asthma, Allergy \& Respiratory Science, King's College London School of Medicine, Guy's Hospital, London, UK

${ }^{4}$ Brighton and Sussex Medical School, Brighton, UK

\begin{abstract}
Background: Incidents of severe and fatal anaphylaxis to accidentally ingested food allergens are increasing Individuals are more likely to encounter difficulties when eating away from home. In restaurants, front-of-house and kitchen staff may be called upon to provide information about ingredients or ensure certain food allergens are excluded from dishes. Following a series of reactions related to the accidental ingestion of peanuts in curries we assessed food allergy awareness and allergen avoidance practices amongst the staff of Asian-Indian restaurants.
\end{abstract}

Methods: A questionnaire survey was administered by telephone to one member of staff in each restaurant.

Results: Fifty percent (40/80) of restaurants participated. Responders included managers, owners, waiters and chefs. Most $(90 \%)$ had received food hygiene training, but only $15 \%$ food allergy training. $25 \%$ could name three common food allergens. 3 in 4 listed nuts, but less than 1 in 5 mentioned peanuts. Common misunderstandings included $60 \%$ of staff believing an individual experiencing an allergic reaction should drink water to dilute the allergen. A less prevalent, but perhaps more concerning, was the misunderstanding that cooking food would prevent it causing an allergic reaction (25\%). Despite poor knowledge, all respondents were comfortable and $65 \%$ were "very comfortable" with providing a "safe" meal for a customer with a food allergy. $60 \%$ expressed interest in future food allergy training.

Conclusions: Despite high confidence in their own understanding of allergy, many staff lacked the knowledge to provide "safe" meals for food allergic customers. Traditionally tree nuts are a common ingredient in Asian-Indian dishes cuisine and there was widespread, but not universal, awareness of tree nuts as a common allergen. Peanuts were less commonly recognised as a common allergen, an observation of extreme concern as peanuts are being substituted for tree nuts as they are cheaper and avoid having to inflate meal prices. Our data highlights the need for greater training of restaurant staff. In parallel, food allergic customers need to exercise vigilance when making meal choices and develop skills to order a safe meal. The management of allergy is multifaceted, and this study indicates the importance of health professionals working beyond the clinical setting to collaborate with colleagues in the hospitality industry, public health and environmental health in coordinated endeavours to improve patient safety.

Keywords: Anaphylaxis; Food allergy; Nut allergy; Restaurant; United Kingdom

\section{Background}

\section{The problem of food allergy and dining out}

On average six fatal incidences of anaphylaxis to food allergens are reported in the UK each year [1] and the FDA website quotes 150 deaths for the United States [2]. However the true incidence may be higher, and of course these figures exclude any 'near misses' following exposure. Patients are more at risk of unintentional exposure to food allergens when routine is disrupted, for example during festive eating or dining away from home [3] and in restaurants [4,5]. In a study of 48 deaths from food allergens between 1999 and 2006, 18 people had died after consuming catered food [3].

This disproportionate number of deaths when eating out is in part due to restaurants not being required by law to specify on their menu whether there are specific allergenic ingredients in their dishes. Peanuts are an important cause of severe systemic and fatal food allergic reactions, particularly in adolescents and young adults [6,7]. A recent study has shown that one in five peanut allergy customers were risking anaphylaxis by visiting a takeaway establishment [8].

\section{The situation in leicester}

Leicester is a culturally rich and diverse city in the East Midlands, UK, with many restaurant choices available to its population of 280,000
[9]. A particularly popular choice in Leicester is Asian-Indian cuisine; these restaurants emerged in the 1970s in response to a growing AsianIndian population, which now totals 72,000 people [9]. There are 80 such restaurants in the city and surrounding area and in the spring of 2008 there were a number of reports of peanut allergy individuals experiencing anaphylaxis after eating the same curries which they had previously eaten without any adverse effect, this was attributed to the substitution of increasingly costly almonds with cheaper peanuts in such recipes as chicken korma or lamb passanda [10,11]. Previous studies have looked into restaurant staff awareness of food allergy and noted a deficit [12-14] and we wondered if a lack of understanding of food allergy by the restaurant staff, in particular peanut allergy, may have led to the potential danger of peanut substitution not being recognised.

*Corresponding author: Helen Smith, Division of Primary Care and Public Health, Brighton \& Sussex Medical School, Mayfield House, Village Way, Brighton BN2 1AL, United Kingdom, Tel: +44-1273 644102; E-mail: h.e.smith@bsmas.ac.uk

Received April 01, 2013; Accepted June 19, 2013; Published June 25, 2013

Citation: Common LAR, Corrigan CJ, Smith H, Bailey S, Harris S, et al. (2013) How Safe is your Curry? Food Allergy Awareness of Restaurant Staff. J Allergy Ther 4: 140. doi:10.4172/2155-6121.1000140

Copyright: (C) 2013 Common LAR, et al. This is an open-access article distributed under the terms of the Creative Commons Attribution License, which permits unrestricted use, distribution, and reproduction in any medium, provided the original author and source are credited. 
This study is the first to focus on one specific type of food establishment in response to a public health problem. The presentation of a meal is a team effort, and the team is only as strong as the weakest member, hence the importance of including staff from all roles. In this study we aimed to assess the level of awareness and understanding of food allergy among restaurant staff in Asian-Indian restaurants in a city where there had been a cluster of severe peanut allergic reactions when eating this cuisine.

\section{Materials and Methods}

\section{Objectives}

The primary aim of the study was to perform a telephone questionnaire survey of Indian restaurants in Leicester to determine staff awareness of food allergy using a series of simple, closed questions.

\section{Study sample}

All restaurants in Leicester serving Asian-Indian food $(n=80)$ were identified from a popular online database providing details of all businesses (www.yell.com). Each restaurant was telephoned and asked to participate in the study. The staff member who took the call was then interviewed or, if the timing was inconvenient, the interviewer rang back at a pre-arranged time.

\section{Questionnaire}

The questionnaire consisted 24 brief items (Appendix 1) addressing restaurant characteristics, respondent's personal demographics, food hygiene and allergy training, knowledge of food allergy and comfort dealing with customers with food allergy. Participants were asked to list three common food allergens, 'common' was defined as any of the 14 allergens required by European law (European Directives 2003/89/ EC and 2006/142/EC) to be listed on cartons of pre-packaged food. This list consists of cereals containing gluten, crustaceans, molluscs, eggs, fish, peanuts, nuts, soybeans, milk, celery, mustard, sesame, lupin and sulphur dioxide at levels above $10 \mathrm{mg} / \mathrm{kg}$, or $10 \mathrm{mg} / \mathrm{litre}$, expressed as $\mathrm{SO}_{2}$. The questionnaire took approximately 10 minutes to administer.

\section{Statistical analysis}

Responses were coded and analysed using a statistical software package (SPSS version 13). Differences between groups were examined using Fisher's exact test and confidence interval analysis.

\section{Results}

\section{Responses and demographics of participants}

Among the 80 restaurants telephoned, 40 participated (50\%), 5 declined (6\%) and $35(44 \%)$ were not contactable during the time periods allocated for data collection. The responsibilities of respondents were managers $(45 \%)$, waiters $(25 \%)$, owners $(12.5 \%)$, chefs $(12.5 \%)$ and supervisors (5\%). Some restaurant staff who answered the telephone referred the researcher's call to their manager rather than answer questions themselves, despite a reassurance of anonymity and confidentiality. The participants ranged from 17 to 65 years old, all were men with one exception.

\section{Knowledge and education regarding food allergy}

Most (90\%) had received food hygiene training, but only $15 \%$ food allergy training, and of those that had received food allergy training it had been incorporated into food hygiene or catering course. The majority of respondents had heard of food allergy (95\%), but fewer recalled ever encountering someone with a food allergy (58\%). Staff's experience of food allergy came predominantly from customers, but two participants reported their own children had a diagnosis of food allergy. Reflecting on the preceding three years, $90 \%$ respondents did not recall any food allergy-related emergency in their restaurant.

Twenty five percent of the participants were able to correctly name three 'common' food allergens. The 'common allergens listed were nuts (32), milk (12), gluten (10), peanuts (7), fish (4), crustacean (1), sesame (1). There were many misconceptions about food allergy among the restaurant staff (Figure 1):

- $60 \%$ believed that if a customer was having an allergic reaction it was appropriate to serve them water to 'dilute' the allergen;

- $25 \%$ believed that cooking the food would prevent it from causing an allergic reaction;

- $23 \%$ thought it was safe for customers with food allergy to eat a small amount of the allergen;

- $13 \%$ believed that removing an allergen from a finished meal containing the allergen would render the meal safe for the allergic customer to consume;

- $8 \%$ did not think a food allergic reaction could cause death.

\section{Knowledge and comfort levels}

A large proportion of staff professed a high degree of confidence in their ability to provide a safe meal for a customer with food allergies (Figure 2), with the majority reporting they were "very comfortable" (65\%) and no one stated they were to any degree uncomfortable. One chef working in a buffet style restaurant described feeling "very comfortable" as the dishes left his kitchen but reported only feeling "comfortable" overall because of the potential for cross-contamination by careless practice as customers helped themselves to the food. Another participant commented that he would strongly discourage a peanut allergic customer from eating at his restaurant because peanuts were used and he could not confidently exclude cross-contamination in the process of preparation. Respondents expressing greater confidence in providing a safe meal for an allergic customer tended to score higher on the true/false questions (Fisher's exact test $\mathrm{p}=0.026$, difference $43.1 \%$, (95\% CI: $0.072,0.664)$ ), but were not any better than their peers

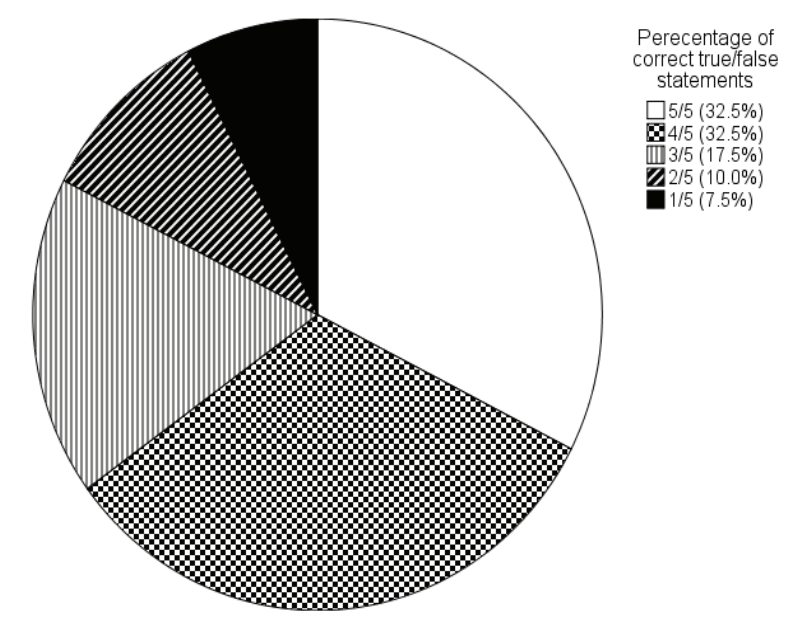

Figure 1: Percentages of respondents providing correct responses to the five true/false statements in the questionnaire. 


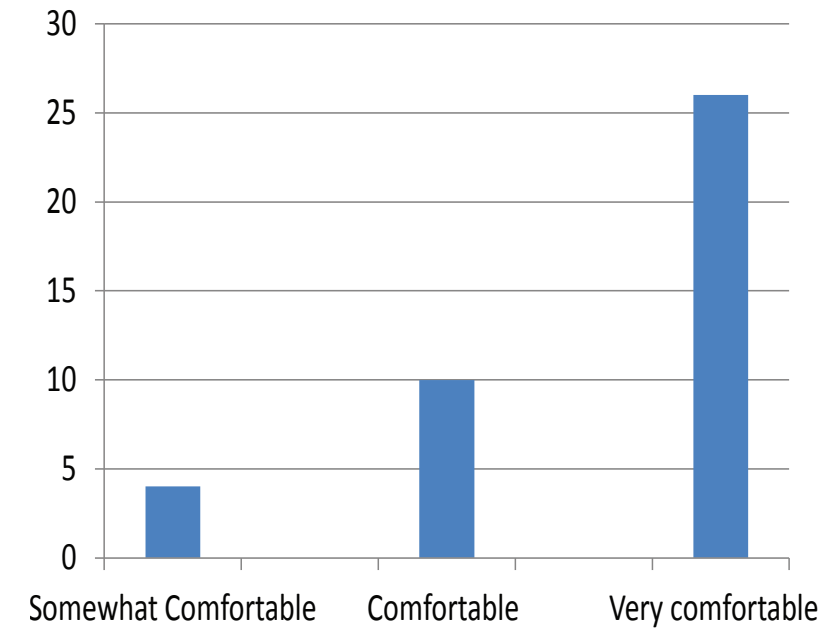

Foot note: No respondent stated they were 'somewhat uncomfortable' or 'very uncomfortable'

Figure 2: Respondents self expressed degree of comfort in providing food for customers with food allergies.

when correctly naming three common food allergens (Fisher's exact test $\mathrm{p}=0.868$, difference $6.9 \%$, (95\% CI: $-0.201,0.395)$ ).

\section{Discussion}

This study demonstrates some worrying gaps in restaurant staff's knowledge of food allergy. Very few staff had received specific formal training on how to prepare and serve food for their allergic customers. One third of respondents answered the true-false knowledge questions correctly. Only one in four staff was able to correctly name three common food allergens. Despite alarming gaps in knowledge all staff expressed 'comfort' in providing a safe meal to food allergic customers.

The provision of a safe meal for food allergic patients is a team activity dependent on everyone having sufficient level of awareness and knowledge to ensure safe delivery of the food. The waiters and servers are in direct communication with diners and they must be relied upon to ascertain the customer's needs. But even if dietary requirements are clearly understood, poor communication between front of house and kitchen staff may contribute to a meal being served which is not safe for the customer. An important strength of this study was the inclusion of employees in different roles. As the approach was by telephone, the majority of the respondents were managers and waiters; alternative methods may be needed to capture the knowledge and practice of more "back room" staff, including those involved in food preparation, cleaning and dishwashing.

Nonetheless, the telephone questionnaire survey did work well as a tool to elicit information quickly and cheaply. A response rate of $50 \%$ is very good for a study where there is no previous relationship with the survey respondents, no incentive offered and where participation interrupts the respondents' work. In the main, lack of participation reflected difficulty in identifying a mutually convenient time for both the participants and researchers to complete the survey rather than an unwillingness to participate. The findings from such an easily conducted survey can inform the tailoring of educational packages for the restaurants targeted. We acknowledge the limitation of our study being dependent on self-reported practice, rather than objective observation of food separation and avoidance of cross-contamination. Future research should address practice in the kitchen, including evidence of clear protocols and facilities for provision of specific allergen-free foods. Exploration of the customer experience and perspective could also inform initiatives to reduce the risks of dining-out for the food allergic patient.

How safe is your curry? The deficits in knowledge highlighted in these Asian-Indian restaurant are not dissimilar to those observed in other restaurants [12-17]. Traditionally tree nuts (particularly almonds and cashews) are a common ingredient in Asian-Indian cuisine and there was widespread, although not universal, awareness amongst restaurant staff of tree nuts as a common allergen. Peanuts were less commonly recognised as a common allergen, an observation of extreme concern when peanuts are being substituted for expensive tree nuts as a way of avoiding meal price inflation. In this context there is a need for restaurant staff to be aware that tree nuts and peanuts are distinct and that a customer who can safely eat tree nuts may not be able to tolerate peanuts. In this setting ingredient substitution had been stimulated by rising costs, but it can also accompany change in supplier or chef. Whoever is primarily responsible for adjustments in ingredients needs to recognise the necessity of alerting everyone else in the team to change. In parallel there remains a need for food allergic customers to exercise vigilance when making meal choices and not to assume that if meal choice was previously safe that it will remain so. As clinicians we need to educate our patients about potential pitfalls that may await them in restaurants. Patients need knowledge about their food allergy but also skills training in how to negotiate a safe restaurant meal. A heightened awareness of the gap between the confidence and competence of restaurant staff to protect allergic people may encourage the allergic diner to be more persistent and thorough in their enquiry.

The management of allergy is multifaceted, and this study indicates the importance of health professionals working beyond the clinical setting to collaborate with colleagues in the hospitality industry, public health and environmental health in coordinated endeavours to improve patient safety.

It was health care staff that first became aware of the increasing prevalence of allergic symptoms and anaphylaxis in peanut allergic patients following a curry meal that the patient had previously been able to enjoy without symptoms. To minimise further incidences restaurants need to be alerted quickly to the acute problem observed and also made aware of forthcoming opportunities for staff food allergy training. Integrating food allergy training in the basic generic food hygiene training is probably the most pragmatic way to get near universal coverage in an industry which has high staff turnover and narrow profit margins.

In addition there is potential for food enforcement and environmental health officers to play an important part in raising awareness of food allergy when carrying out inspections. With adequate training they could cascade up-to-date information about food allergy to the restaurants they visit [18]. Kite marking individual establishments for their food allergy knowledge and practice may help the food allergic customer select which restaurants to use, but vigilance is still required on the part of the customer to communicate their dietary needs effectively and risk-assess the dining environment.

In conclusion, while Asian-Indian restaurants have been the focus of this paper, evidence from other studies indicates that the risk of food allergic reactions when eating out is not limited to this type of cuisine. Wider, statutory information would augment awareness and safe practice across a range of restaurants, and afford the food allergic customer greater choice, safety and comfort when eating out. In order 
Citation: Common LAR, Corrigan CJ, Smith H, Bailey S, Harris S, et al. (2013) How Safe is your Curry? Food Allergy Awareness of Restaurant Staff. J Allergy Ther 4: 140. doi:10.4172/2155-6121.1000140

to ensure this, good education is needed in a way that is accessible, cheap and relevant to all catering staff. The management of food allergy is multifaceted and this paper emphasises the importance of working beyond the clinical setting in our endeavours to improve the well-being of patients.

\section{Competing Interests}

No conflicts of interest to declare. No funding was obtained for this study which was undertaken as part fulfilment for the award of MSc Allergy from the University of Southampton.

\section{Author Contributions}

Lucy Common carried out all telephone questionnaires and collected data. Lucy Common, Judith Holloway and Christopher Corrigan designed and supervised the research project as part of Lucy Common's MSc Allergy dissertation. Helen Smith and Sam Bailey helped with questionnaire development. Scott Harris advised on statistical analysis of data. All authors contributed to manuscript writing and revision.

\section{Acknowledgements}

The researchers would like to thank the staff in the Asian-Indian restaurants in Leicester, for giving up their time to answer questions for the study. Many thanks to Hazel Gowland from the Anaphylaxis Campaign for providing background information for the study.

\section{References}

1. Pumphrey RS (2000) Lessons for management of anaphylaxis from a study of fatal reactions. Clin Exp Allergy 30: 1144-1150.

2. http://www.fda.gov/Food/LabellingNutrition/FoodAllergensLabeling/ GuidanceComplianceRegulatorylnformation/ucm106187.html

3. Pumphrey RS, Gowland MH (2007) Further fatal allergic reactions to food in the United Kingdom, 1999-2006. J Allergy Clin Immunol 119: 1018-1019.

4. Bock SA, Muñoz-Furlong A, Sampson HA (2001) Fatalities due to anaphylactic reactions to foods. J Allergy Clin Immunol 107: 191-193.
5. Sicherer SH, Noone SA, Muñoz-Furlong A (2001) The impact of childhood food allergy on quality of life. Ann Allergy Asthma Immunol 87: 461-464.

6. Hourihane JO (2002) Recent advances in peanut allergy. Curr Opin Allergy Clin Immunol 2: 227-231.

7. Bock SA, Muñoz-Furlong A, Sampson HA (2007) Further fatalities caused by anaphylactic reactions to food, 2001-2006. J Allergy Clin Immunol 119: 10161018.

8. Leitch IS, Walker MJ, Davey R (2005) Food allergy: gambling your life on a take-away meal. Int J Environ Health Res 15: 79-87.

9. Leicester City Council: Area profile for the city of Leicester- Demographic and Cultural from 2001 Census.

10. BSACI (British Society of Allergy and Clinical Immunology): Warning articleIncreased reactions to hidden peanut in curry.

11. (2009) BBC: Curry worry over peanut allergy. BBC news report broadcast 31 March 2009.

12. Pratten J, Towers N (2003) Food Allergies and the UK catering Industry. A study of the training needs for the industry to serve those with food allergies. Journa of European Industrial Training 28: 490-498.

13. Ahuja R, Sicherer SH (2007) Food-allergy management from the perspective of restaurant and food establishment personnel. Ann Allergy Asthma Immunol 98: 344-348.

14. Bailey S, Albardiaz R, Frew AJ, Smith H (2011) Restaurant staff's knowledge of anaphylaxis and dietary care of people with allergies. Clin Exp Allergy 41 713-717.

15. Machin D, Campbell J (2005) Design Studies for Medical Research. Chichester Wiley.

16. Food Standards Agency: Allergy labelling-which ingredients?

17. Furlong TJ, DeSimone J, Sicherer SH (2001) Peanut and tree nut allergic reactions in restaurants and other food establishments. J Allergy Clin Immunol 108: 867-870.

18. House of Lords Science and Technology Committee (2007) Allergy, Volume I: report. London: Authority of the House of Lords. 